\title{
Implication of replicative stress-related stem cell ageing in radiation-induced murine leukaemia
}

\author{
N Ban ${ }^{*, 1}$ and M Kai' \\ 'Department of Health Sciences, Oita University of Nursing and Health Sciences, 2944-9 Megusuno, Oita 870-I 201, Japan
}

\begin{abstract}
BACKGROUND: The essential aetiology of radiation-induced acute myeloid leukaemia (AML) in mice is the downregulation of the transcription factor PU.I. The causative mutation of the PU.I -endocing Sfpil gene consists mostly of C:G to T:A transitions at a CpG site and is likely to be of spontaneous origin. To work out a mechanism underlying the association between radiation exposure and the AML induction, we have hypothesised that replicative stress after irradiation accelerates the ageing of haematopoietic stem cells (HSCs), and the ageing-related decline in DNA repair could affect the spontaneous mutation rates.

METHODS: Mathematical model analysis was conducted to examine whether and to what extent the cell kinetics of HSCs can be modified after irradiation. The haematopoietic differentiation process is expressed as a mathematical model and the cell-kinetics parameters were estimated by fitting the simulation result to the assay data.

RESULTS: The analysis revealed that HSCs cycle vigourously for more than a few months after irradiation. The estimated number of cell divisions per surviving HSC in 3 Gy-exposed mice reached as high as ten times that of the unexposed.

INTERPRETATION: The mitotic load after $3 \mathrm{~Gy}$ irradiation seems to be heavy enough to accelerate the ageing of HSCs and the hypothesis reasonably explains the leukaemogenic process.

British Journal of Cancer (2009) I 01, 363-37I. doi:I0.1038/sj.bjc.6605I35 www.bjcancer.com
\end{abstract}

Published online 9 June 2009

(c) 2009 Cancer Research UK

Keywords: replicative stress; stem cell ageing; radiation; acute myeloid leukaemia; $\mathrm{C} 3 \mathrm{H} / \mathrm{He}$ mice; mathematical model

There is substantial evidence that ionising radiation can cause various types of malignancies. Among them, leukaemia is noteworthy because of the high relative risk and the short latency (Preston et al, 1994). The mechanism of radiation leukaemogenesis, however, is not yet fully explained despite recent advances in the understanding of genetic alterations in leukaemic cells. It has been speculated that leukaemia-specific gene rearrangements (Schoch and Haferlach, 2002; Mrózek et al, 2004) are attributable to the misrepair of initial DNA damage caused by radiation. This notion, however, suffers from the low probability of such events given the random nature of radiation-induced DNA damage. It is also difficult to rationalise the latency period for the disease. Radiation-induced delayed gnomic instability could explain the leukaemogenic process more plausibly, but there is no conclusive evidence of its involvement (Morgan, 2003). The findings of healthy carriers of leukaemia-specific gene rearrangements have lead to a further bold hypothesis that only those carriers are at risk for developing leukaemia when exposed to radiation (Nakamura, 2005).

Radiation-induced acute myeloid leukaemia (AML) in some strains of mice serves as a well-established animal model to explore this issue. The incidence increases with doses up to $3 \mathrm{~Gy}$ and the symptoms of the affected mice are similar to those found in human AML (Upton et al, 1958; Major, 1979; Mole et al, 1983; Resnitzky et al, 1985; Seki et al, 1991). The leukaemic cells usually carry a

*Correspondence: Dr N Ban; E-mail: ban@oita-nhs.ac.jp

Received 18 February 2009; revised 21 May 2009; accepted 21 May 2009; published online 9 June 2009 deletion of chromosome 2 (Hayata et al, 1983; Trakhtenbrot et al, 1988; Rithidech et al, 1993; Clark et al, 1996) and a mutation of the Sfpil gene on the retained homologue (Cook et al, 2004; Suraweera et al, 2005; Hirouchi et al, 2008). These genetic changes result in downregulation of the transcript PU.1, which is crucial for normal myeloid differentiation (Cook et al, 2004). Although the Sfpi1 mutations are often accompanied by additional genetic alterations, such as amplification of $M y c$ (Rosenbauer et al, 2004; Hirouchi et al, 2008), studies with genetically engineered mice show that downregulation or inactivation of PU.1 is sufficient to induce AML (Rosenbauer et al, 2004; Metcalf et al, 2006). Therefore, radiation is considered to be responsible for either or both of two genetic events, the deletion of chromosome 2 and the mutation of Sfpil.

Several studies have provided circumstantial evidence that radiation can induce AML-type deletions of chromosome 2 (Hayata, 1985; Trakhtenbrot et al, 1988; Ban et al, 1997; Peng et al, 2009), even though it is inconclusive whether the aberrations arise as a consequence of initial DNA damage or through delayed chromosomal instability (Plumb et al, 1998; Bouffler et al, 2001; Boulton et al, 2001). As for the mutation of Sfpi1, however, there is no direct data about the involvement of radiation in its induction. The Sfpi1 mutations found in AMLs are mostly point mutations at codon 235 of the DNA-binding Ets domain. The majority of them are C:G to T:A transitions at a CpG site (Cook et al, 2004; Suraweera et al, 2005; Hirouchi et al, 2008), the most common type of spontaneous mutations (Douglas et al, 1994; Ushijima et al, 1994). In the case of radiation-induced mutations, large-scale deletions are most frequent (Thacker, 1986; Sankaranarayanan, 1991). Point mutations might predominate among late-arising mutations (Little, 2000), but transversions rather than transitions 
are expected given that oxidative stress-related genotoxicity directly contributes to those mutations (Wright, 1998; Busuttil et al, 2003). For these reasons, the Sfpil mutations of murine AML are likely to be of spontaneous origin.

Normal cells equipped with various forms of repair machinery can replicate and maintain DNA with great accuracy. Nevertheless, DNA is damaged and mutated on repeated replications. This is the case even in haematopoietic stem cells (HSCs) because they accumulate DNA damage after repeated rounds of replications and those mutations are associated with stem cell ageing (Kamminga and de Haan, 2006; Sharpless and DePinho, 2007). With evidence of decline in HSC functional capacity among mice deficient in DNA repair or telomere maintenance, accumulation of DNA damage is postulated to be a cause of stem cell ageing (Rossi et al, 2007). At the same time, the mutation accumulation would be accelerated as the cells age because HSCs from old wild-type mice show the decreased expression of DNA repair and maintenance genes (Chambers et al, 2007). The aged, damaged stem cells eventually lose repopulating capability and stem cell function, but they continue to proliferate with compromised genomic integrity if they could escape extinction. In this regard, early studies on haematopoietic effects of radiation present intriguing data. The frequency of CFU-S is depressed while the level of cycling is increased over the lifespan of x-irradiated mice (Tejero et al, 1988; Lorimore and Wright, 1990). If HSCs also cycle at enhanced rates for a prolonged period of time, the replicative stress will result in premature ageing. The aged stem cells would show a decline in DNA damage repair capacity and are prone to spontaneous mutations.

In this study, we have used a mathematical model analysis to examine whether and to what extent radiation cause replicative stress in HSCs. The differentiation process of haematopoietic cells was expressed in a mathematical model. The cell-kinetics parameters were estimated by fitting the simulation result to the experimental data of CAFC (cobblestone area forming cell) and CFU-G/M (colony forming unit-granulocyte/macrophage) assays. The analysis showed the upregulated cell kinetics for HSCs, which seemed to be sufficient to accelerate ageing of them. Possible leukaemogenic processes have been discussed based on the results, and we have found the most plausible explanation is that the replicative stress-related stem cell ageing plays a role elevating spontaneous mutation rates of HSCs and their progeny.

\section{MATERIALS AND METHODS}

\section{Model structure}

Figure 1 illustrates the hierarchy of haematopoietic cells. Although various assay techniques have been developed to measure the frequencies of those cells, the assay data do not necessarily represent the single cell types in the figure. For example, cycling HSCs are not identified as LT-HSC owing to the cell-cycle dependent decline in engraftment ability (Habibian et al, 1998; Passegué et al, 2005; Bowie et al, 2006). There are also transient or fuzzy states between cell types. Applying a linear reservoir model cannot demonstrate massive cell growth through the differentiation process unless unrealistic parameters are assumed. These facts indicate that a simulation with a straightforward modelling of the hierarchy shown in Figure 1 is hard to verify experimentally.

To overcome these problems without compromising scientific exactitude, we have constructed a mathematical model of myelomonocytic haematopoiesis as shown in Figure 2. In this model, HSCs are divided into quiescent HSCs and cycling HSCs. The former are LT-HSCs in $\mathrm{G}_{0}$ phase, which can be quantified by a repopulation assay such as day-28 CAFC. Multipotent progenitor (MPP) in Figure 2 represents ST-HSC and MPP in a limited sense. Both have transient in vivo multilineage potential and are thought

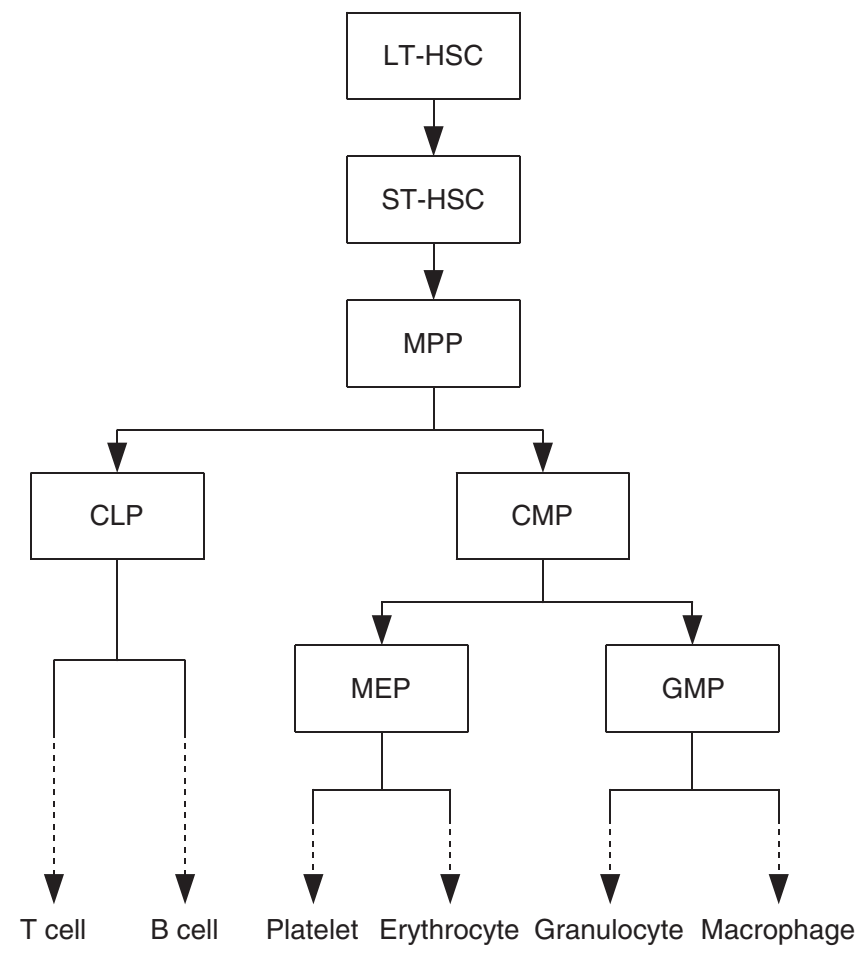

Figure I Hierarchy of haematopoietic cells. Long-term reconstituting haematopoietic stem cells (LT-HSCs) are the source of all blood-cell lineages. Subsequent short-term reconstituting stem cells (ST-HSCs) have a limited self-renewal activity and give rise to multipotent progenitors (MPPs) MPPs produce common lymphoid progenitors (CLPS) and common myeloid progenitors (CMPs). CMPs further differentiate into megakaryocyte/erythroid progenitors (MEPs) and granulocyte/macrophage progenitors (GMPs)

to share similar cell kinetics. Day-14 CAFC can be an indicator of these cell types as well as cycling HSCs (Ploemacher et al, 1991). Common myeloid progenitor (CMP) is equivalent to CFU-GEMM and GMP includes CFU-GM, CFU-G, and CFU-M. The ordinary CFU-G/M assay, therefore, gives a measure of those cells. Each cell compartment has a recurrent flow (self-renewal activity), but only HSCs are presumed to be capable of complete replenishment.

\section{Mathematical description}

In Figure 2, quiescent HSCs recruited into the cell cycle (cycling HSCs) self-renew or differentiate into MPPs. In the case of selfrenewal, the HSC returns to the quiescent state or continues to cycle. As self-renewal and differentiation of cells take place on mitoses, these processes are described by ordinary differential equations with respect to time as

$$
\begin{aligned}
& \dot{N}_{1}=-r_{1} N_{1}+2 P_{21} r_{2} N_{2} \\
& \dot{N}_{2}=r_{1} N_{1}-r_{2} N_{2}+2 P_{22} r_{2} N_{2}
\end{aligned}
$$

where $N_{1}$ is the number of quiescent HSCs, $N_{2}$ the number of cycling HSCs, $r_{1}$ the rate of a quiescent HSC transferring to the cell cycle, $r_{2}$ the mitotic rate of cycling HSCs, $P_{21}$ the probability of a self-renewed HSC returning to the quiescent state, and $P_{22}$ the probability of a self-renewed HSC continuing to cycle.

Multipotent progenitor is a progeny of HSC and produces two types of progenitors, common lymphoid progenitor and CMP. The rate of change of MPP frequency is then written as

$$
\dot{N}_{3}=2 P_{23} r_{2} N_{2}-r_{3} N_{3}+2 P_{33} r_{3} N_{3}
$$




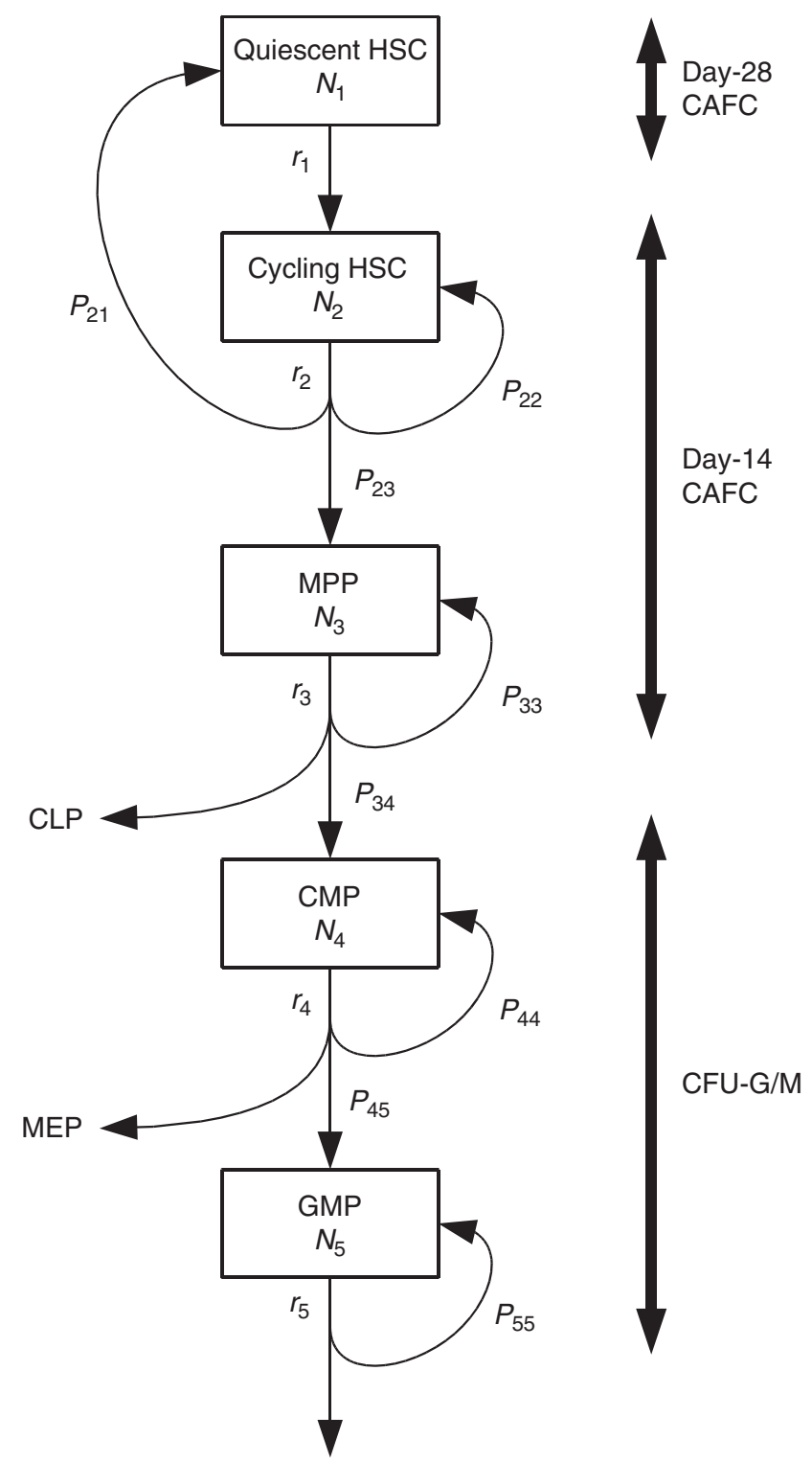

Figure 2 Framework of mathematical model for myelomonocytic haematopoiesis. HSCs that have long-term repopulating ability are mostly in the $G_{0}$ phase and these cells are denoted as quiescent HSCs. Quiescent HSCs recruited into the cell cycle (cycling HSC) replenish themselves or differentiate into MPPs, CMPs, and GMPs in sequence. Equivalent cells in the assays are shown on the right side. $N$ denotes the number of cells, $r$ the transfer/mitotic rate, and $P$ the branching probability.

where $N_{3}$ is the number of MPPs, $r_{3}$ the mitotic rate of MPP, $P_{23}$ the probability of an HSC differentiating into MPP, and $P_{33}$ the selfrenewal probability of MPP $(<0.5)$. Temporal variations of CMPs and GMPs can be described in the same manner.

\section{Simulation of haematopoiesis}

Parameter values used in the simulation are summarised in Table 1. The steady-state condition was assumed in unexposed mice and the values of $r$ were estimated from literature data of BrdU incorporation in vivo (Bradford et al, 1997; Sudo et al, 2000; Passegue et al, 2005). The branching probability $P$ for the selfrenewal of each cell type was determined such that the equilibrium stationary state demonstrates the average values of the CAFC assay
Table I Parameter values used in the simulation

\begin{tabular}{|c|c|c|c|}
\hline Parameter & Steady state ${ }^{a}$ & Recovery phase $^{b}$ & References $^{c}$ \\
\hline$r_{1}$ & $0.03[/ d]$ & Variable & $\begin{array}{l}\text { Bradford et al (1997); } \\
\text { Sudo et al (2000) }\end{array}$ \\
\hline$r_{2}$ & 0.8 [/d] & Variable & Passegué et al (2005) \\
\hline$r_{3}$ & $0.55[/ \mathrm{d}]$ & Variable & Passegué et al (2005) \\
\hline$r_{4}$ & \multicolumn{2}{|c|}{$1.9[/ \mathrm{d}]$} & Passegué et al (2005) \\
\hline$r_{5}$ & \multicolumn{2}{|c|}{$2.5[/ \mathrm{d}]$} & Passegué et al (2005) \\
\hline$P_{21}$ & $0.5-P_{22}$ & Variable & \\
\hline$P_{22}$ & 0.462 & Variable & \\
\hline$P_{23}$ & \multirow{3}{*}{\multicolumn{2}{|c|}{$\begin{array}{c}1-P_{21}-P_{22} \\
0.480 \\
0.5\left(1-P_{33}\right)\end{array}$}} & \\
\hline$P_{33}$ & & & \\
\hline$P_{34}$ & & & \\
\hline$P_{44}$ & \multirow[t]{2}{*}{0.457} & Variable & \multirow{3}{*}{$\begin{array}{l}\text { Spangrude and } \\
\text { Johnson (1990) }\end{array}$} \\
\hline$P_{45}$ & & $\left(I-P_{44}\right)$ & \\
\hline$P_{55}$ & \multicolumn{2}{|c|}{0.320} & \\
\hline
\end{tabular}

Values for the unexposed steady state. 'Values for 3 Gy-exposed mice. Parameters modulated in response to haematopoietic demands are denoted as 'variable'. 'References for the values or the relational expressions. For details, see the Supplementary material.

and the CFU-G/M assay in the unexposed mice. Other $P$-values were calculated by the relational expressions in Table 1 (Spangrude and Johnson, 1990). Details about the parameter values are given in the Supplementary material.

The number of cells in each compartment in the stationary state was calculated by assuming the population size of quiescent HSCs in an adult mouse to be $1 \times 10^{4}$ (Eaves et al, 1997). The cell numbers were multiplied by survival fractions to estimate the number of surviving cells just after $3 \mathrm{~Gy}$ x-irradiation. Survival fractions for MRA [CFU-S-12], CFU-S-12, CFU-S-7, and CFU-C were calculated by the linear-quadratic model of Meijne et al (1991) and were applied to quiescent HSC, cycling HSC/MPP, CMP, and GMP, respectively. The surviving cell numbers were set as the initial values and the time course of the recovery was simulated. Some parameters were modulated within realistic ranges during the recovery. They are the parameters for HSCs, the mitotic rate of MPP, and the self-renewal probability of CMP. The other parameters were unchanged or followed the relational expressions in Table 1.

Finally, the number of cell divisions of each cell type was estimated based on the simulation result. Setting time to be 0 at irradiation, the cumulative number of cell divisions in the $i$ th cell compartment until time $t$ was calculated by the formula

$$
M_{i}=\int_{0}^{t} r_{i} N_{i} \mathrm{~d} \tau
$$

with the mitotic rate $r_{i}$ and the number of cells $N_{i}$ at time $\tau$.

All calculations were performed in $\mathrm{R}$ using the lsoda function of the odesolve package.

\section{CAFC and CFU-G/M assays}

Male $\mathrm{C} 3 \mathrm{H} / \mathrm{HeN}$ mice were purchased from Japan Clea and maintained under conventional conditions. At 8-10 weeks of age, they were exposed to $3 \mathrm{~Gy}$ of $200 \mathrm{kV}$ X-rays filtered with $0.5 \mathrm{~mm} \mathrm{Cu}$ and $0.5 \mathrm{~mm} \mathrm{Al}$ (dose rate $0.47 \mathrm{~Gy} \mathrm{~min}^{-1}$ ). The irradiated mice as well as age-matched controls were killed at 30,90, 150, and 300 days post irradiation and bone marrow cells were collected from the femora. Animal experiments were performed with the approval of the Research Ethics Committee of Oita University of Nursing and Health Sciences in conformity with applicable laws and regulations. 
For the CAFC assay, bone marrow cells of individual mice were suspended in $\alpha$-MEM (Sigma-Aldrich, Irvine, UK) containing $12.5 \%$ foetal calf serum (ThermoTrace, Melbourne, Australia), $12.5 \%$ horse serum (ThermoTrace), $10^{-5} \mathrm{M}$ hydrocortisone (Sigma-Aldrich), $100 \mathrm{U} \mathrm{ml}^{-1}$ penicillin, and $100 \mu \mathrm{g} \mathrm{ml}^{-1}$ streptomycin (Sigma-Aldrich). The cells were overlaid on MC3T3-G2/PA6 stromal cells (provided by the RIKEN CELL BANK) grown in a collagen-coated 96-well flat-bottom microplate (Nalge Nunc International, Rochester, NY, USA). Six dilution steps of the overlaid cells were made with 3-fold intervals from 1000 to 243000 cells in $150 \mu \mathrm{l}$ culture volume, and 16 wells were used for each dilution. Cultures were maintained at $33^{\circ} \mathrm{C}, 5 \% \mathrm{CO}_{2}$, and fed weekly by a half medium change. On days 14 and 28 of culture, the wells were inspected for cobblestone areas with an inverted microscope TMF (Nikon, Tokyo, Japan). A well was scored as positive if it contained more than one cobblestone area that comprised at least five phase-dark cells. The limdil function of the statmod package for $\mathrm{R}$ was used to find the maximum likelihood solutions of the frequencies of the CAFCs.

Part of the bone marrow cells from each mouse was used for the CFU-G/M assay. The cells were diluted with IMDM (SigmaAldrich) containing $2 \%$ foetal calf serum and were mixed with methylcellulose medium MethoCult GF M3534 (StemCell Technologies, Vancouver, Canada). Two dishes of the semi-solid culture containing $1.5 \times 10^{4}$ bone marrow cells in $1.1 \mathrm{ml}$ were prepared for each mouse and were incubated at $37^{\circ} \mathrm{C}, 5 \% \mathrm{CO}_{2}$. On day 10 of incubation, the number of colonies containing more than 50 cells was counted on an inverted microscope.

\section{RESULTS}

\section{Frequencies of primitive haematopoietic cells}

Figure 3 shows the results of CFU-G/M and CAFC assays. The frequencies of $\mathrm{CFU}-\mathrm{G} / \mathrm{M}$ in the exposed mice are comparable to the unexposed throughout the experimental period, indicating a rapid recovery of the committed progenitors after irradiation. With regard to the CAFC frequencies, data of day-14 cultures for 150 days post irradiation varied so much that the limdil function failed to find maximum likelihood solutions. The day-14 CAFC frequency was also not calculable for a mouse of the control group for 30 days post irradiation because all wells were positive for the cobblestone area. Despite these missing data, Figure 3 clearly shows that the level of primitive CAFCs was suppressed for a few months after exposure. Long-term suppression was remarkable in day-28 CAFCs. The frequency fell down to a tenth of the normal level at 90 days post irradiation and did not fully recover even at 300 days post irradiation.

\section{Simulation of recovery after irradiation}

In the simulation of the recovery process, we first tested for the priority to generate downstream cells rather than self-renewal of HSCs, that is, increasing the branching probabilities for HSCs differentiating into MPPs. This was not effective even in the short term, however, and just exhausted HSCs. Upregulating the transfer/mitotic rates of HSCs and MPPs resulted in quick recovery of CFU-G/M, but the frequency of HSCs was suppressed to a low level at all times if the self-renewal probability of HSC was unchanged. These results show that it is necessary to enhance the self-renewal of HSCs before the committed progenitors are restored. It is also noteworthy that the frequencies of committed cells can vary drastically in response to a subtle change in HSC kinetics, indicating that continuous, fine adjustments are required for the parameters.

Figure 4 displays a simulation result that fits to the assay data. Although the parameters are not determined uniquely, they need to be modulated in a certain way to demonstrate the recovery pattern observed in the experiment. A time course of the parameter changes can be divided into three prominent phases shown in the graph.

Phase I: HSCs and MPPs respond to haematopoietic demands until CFUs-G/M are restored. The probability of HSC self-renewal is increased. Transfer/mitotic rates of HSC and MPP are high.

Phase II: Cell kinetics is downregulated to prevent the overgrowth of CFUs-G/M. The probability of the HSC selfrenewal is suppressed. Transfer/mitotic rates are decreased, but still higher than the normal state.

Phase III: HSCs increase gradually whereas the CFU-G/M frequency remains constant. The probability of the HSC self-renewal is moderately increased, but CMP self-renewal is suppressed. Mitotic rates of HSCs and MPPs are gradually increased with time.

\section{Estimation of the number of cell divisions after irradiation}

The number of cell divisions in each cell compartment was calculated in the course of the simulated recovery process. Figure 5
CFU-G/M

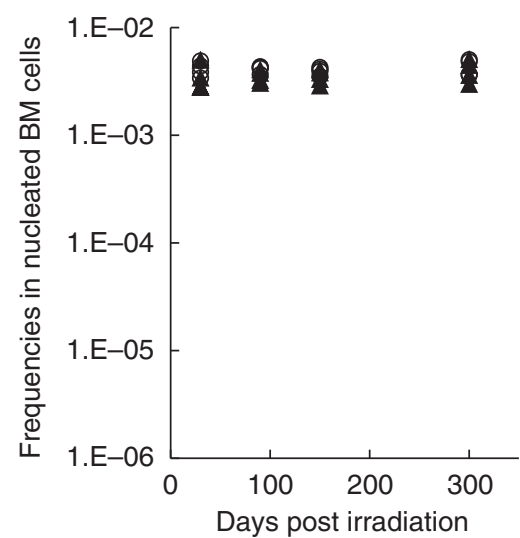

Day-14 CAFC

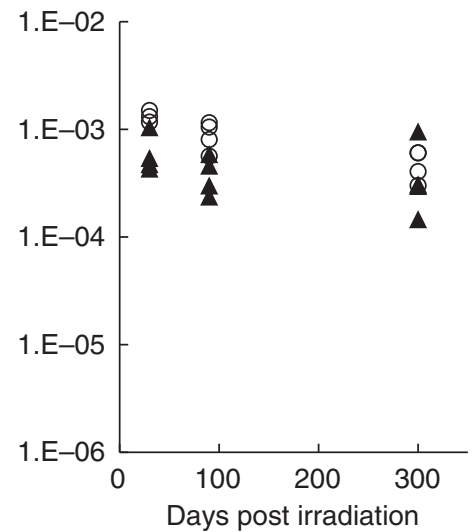

Day-28 CAFC

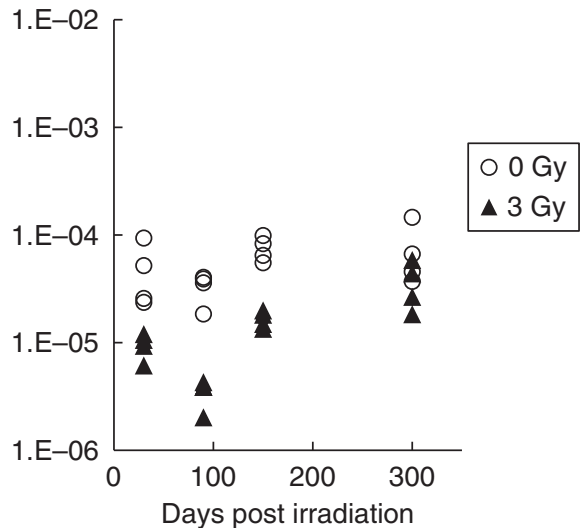

Figure 3 Results of CFU-G/M and CAFC assays. Four mice were used for each experimental condition and the markers represent individual animals. Data are missing for day-14 CAFC of 150 days post irradiation because maximum likelihood solutions were not obtained because of inconsistently varied data (see main text for details). 
shows the cumulative number of cell divisions with or without irradiation. Although the slope of the curve increases for HSCs and MPPs at phase III of the recovery, there were no striking differences from the control group during 300 days after exposure. However, less than $10 \%$ of HSCs survived on exposure to $3 \mathrm{~Gy}$ $\mathrm{X}$-rays, meaning that surviving HSCs bear a high mitotic load to achieve a comparable number of cell divisions as a whole. This was showed by the percentage of cycling HSCs, which were elevated just after irradiation and never returned to a normal level (Figure 6A). The number of cell divisions per surviving HSC was remarkably high in that condition, more than 10 times that from

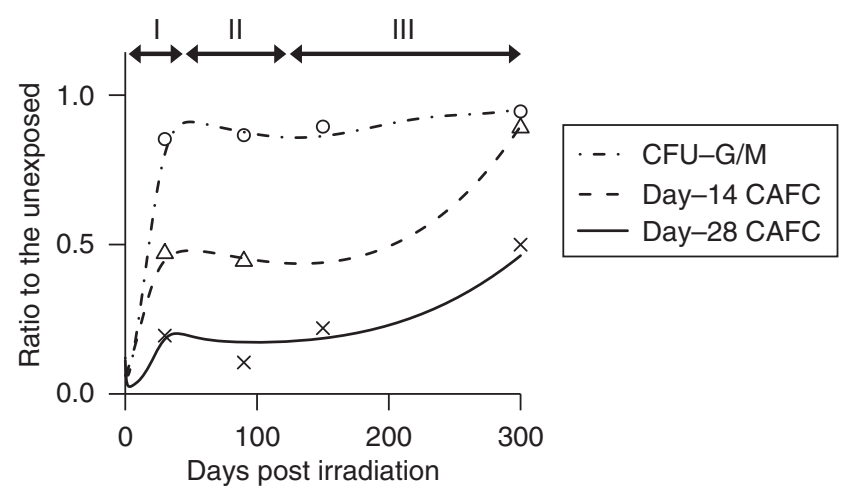

Figure 4 Simulation of temporal changes in CFU-G/M and CAFC frequencies. The lines indicate the simulation results. The markers represent mean values of the experimental data shown in Figure 3 (circle, CFU-G/M; triangle, day-14 CAFC; and cross, day-28 CAFC). 'Variable' parameters were continuously modulated with time in the simulation. The time course of the parameter changes can be divided into three prominent phases and are shown above the graph (see main text for details). unexposed mice (Figure 6B). By 300 days post irradiation, surviving HSCs underwent five times the number of cell divisions that are expected for HSCs from unexposed mice during their entire lifespan, assuming a longevity of 2 years.

\section{DISCUSSION}

We used CAFC assay to get a measure of multipotent haematopoietic cells. The CAFC assay is validated in many applications (e.g., Breems et al, 1994; Parmar et al, 2005) and is said to be more robust than the widely used CFU assay in some conditions (Olesen et al, 2002). Our assay result also demonstrates its robustness showing small inter-individual variations and good agreement in the estimated CAFC frequencies for the unexposed mice with literatures (Ploemacher et al, 1989; de Haan et al, 1997). Although the missing data points in Figure 3 may reflect a limitation of the culture-based limiting dilution assay, the obtained data are regarded reasonable and reliable. Together with the solid result of the CFU-G/M assay, the experimental data provide a good basis for the mathematical simulation.

In the experiment, day-14 CAFCs and day-28 CAFCs revealed long-term suppression after irradiation, although CFUs-G/M did not show noticeable changes. This is because committed cells are preferentially restored to minimise their influence on circulating blood cells, which are essential for life. The mathematical simulation has showed a quick recovery of CFUs-G/M by vigorously cycling HSCs and MPPs just after irradiation, but the emergent situation settled down as the frequencies of committed cells reached a normal level. Once CFUs-G/M were restored, their frequency remained almost constant and the CAFCs started recovering slowly. It is a contradictory situation where HSCs and MPPs proliferate without affecting the frequencies of the progeny cells. The simulation has found that this can only be achieved by upregulating the kinetics of HSCs/MPPs gradually while
HSC

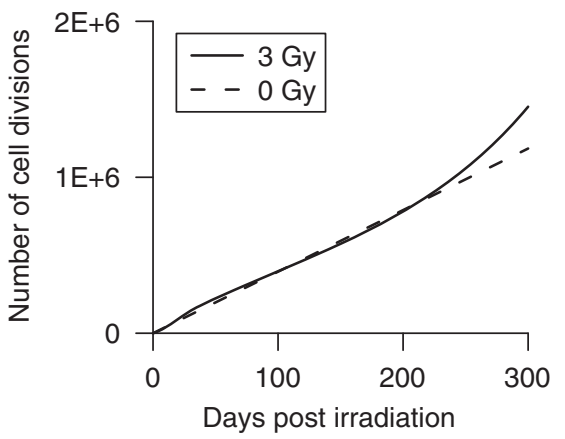

CMP

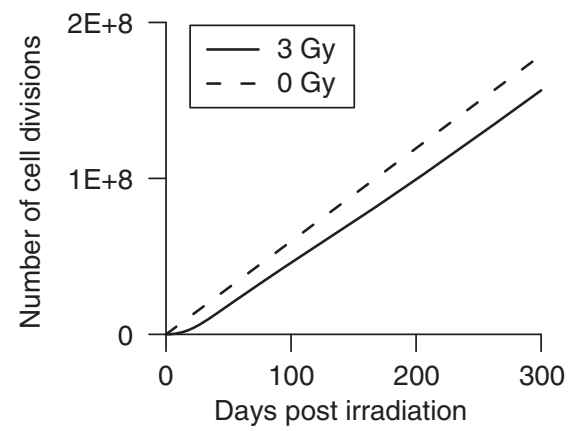

MPP

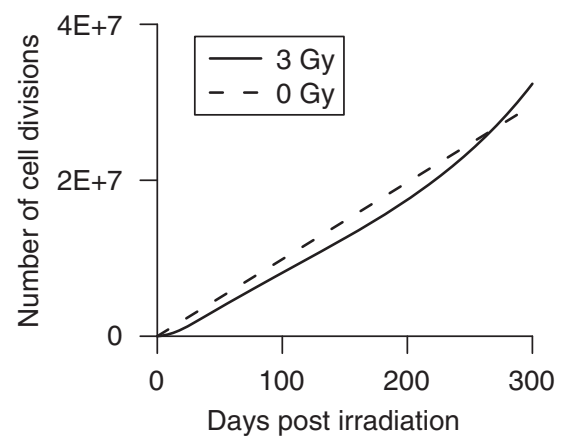

GMP

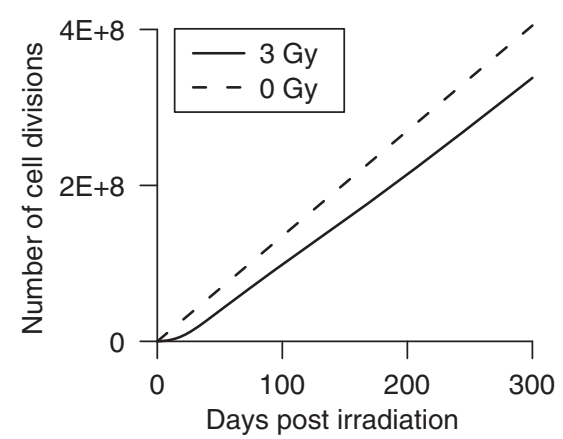

Figure 5 Cumulative number of cell divisions. The number of cell divisions in each cell compartment was calculated using parameter sets that produced the simulation results shown in Figure 4. 

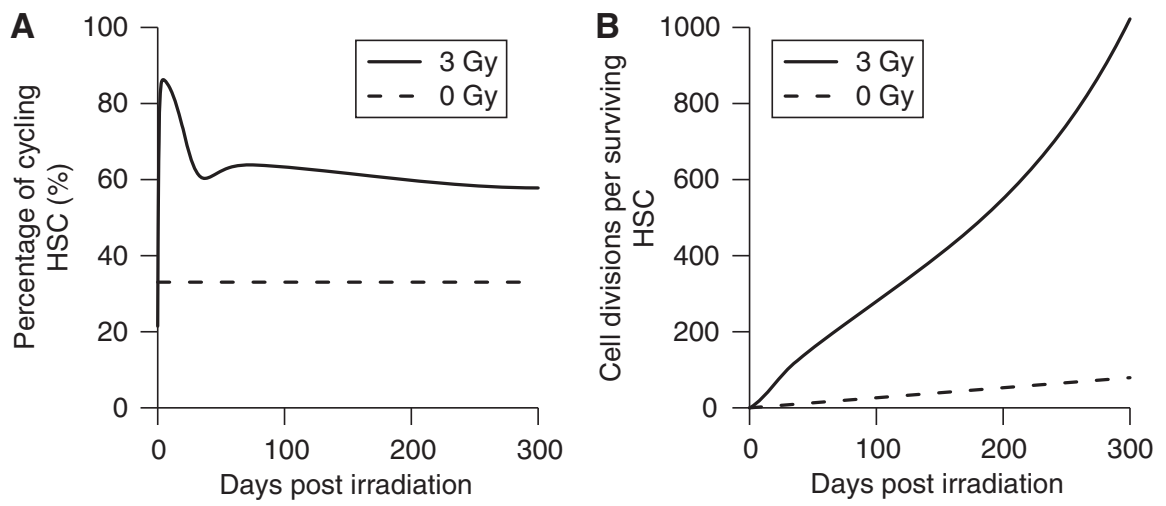

Figure 6 Increased cell cycling in surviving HSCs after irradiation. The percentage of cycling HSCs was calculated from the cell numbers in the quiescentHSC compartment and the cycling-HSC compartment $(\mathbf{A})$. The cumulative number of cell divisions per surviving HSC was calculated by dividing the number of cell divisions of HSCs shown in Figure 5 by the number of HSCs that escaped the cell-killing effect of radiation (B).

suppressing the self-renewal of committed progenitors. The frequency of MPP is suboptimal in that condition even if the cells cycle more rapidly than in the normal state. This indication is consistent with the reported late effects of $\mathrm{x}$-irradiation on CFU-S (Lorimore and Wright, 1990). On the basis of cell kinetics estimated by the simulation, the number of cell divisions of each cell type was calculated. Despite the upregulated cell kinetics for HSCs and MPPs, the cumulative number of cell divisions did not show marked increases. This is because the enhanced proliferation is almost offset by the lower number of cells than in the normal state.

Given the number of cell divisions, it is possible to estimate the spontaneous mutation frequency. Although spontaneous mutations arise from various pathways during normal metabolism, they are fixed through the DNA replication process. If one assumes a constant mutation rate per cell division, mutational events in a cell population follow poisson statistics. Mutation rates in eukaryotic cells are generally $\leqslant 10^{-10}$ mutations per base pair replicated per generation (Kunkel and Bebenek, 2000). As the Sfpil mutations of AMLs are confined to specific positions of exon 5 (Cook et al, 2004; Hirouchi et al, 2008), it is reasonable to presume the AMLspecific Sfpil mutations occur at the rate of up to $10^{-9}$ per cell division in normal cells.

Figure 7 shows the calculated probability of the AML-specific mutational events in a $3 \mathrm{~Gy}$-exposed mouse for that condition. During the 300 days after exposure, at most one or two mutational events are expected in CMPs and GMPs, but practically zero in HSCs and MPPs. Irradiated $\mathrm{C} 3 \mathrm{H} / \mathrm{He}$ mice develop AMLs with a median latency of 450-500 days (Seki et al, 1991). In conditional gene targeting, AMLs appear $23.5 \pm 6.2$ weeks after the inactivation of Sfpil (Metcalf et al, 2006). Taken together, a rough estimate shows that a malignant cell has to appear by 300 days post irradiation in about a half of leukaemia cases ( $>10 \%$ of the $3 \mathrm{~Gy}$ exposed mice). The calculated probability of the mutational events is too low to explain AML induction in mice, considering that the mutation of Sfpi1 has to coincide with the deletion of chromosome 2 to form the malignant cell.

There are some possible explanations that reconcile this inconsistency. One is to reconsider the fundamental hypothesis, presuming the mutation of Sfpil is a consequence of radiation exposure. Mutation frequency of a single gene after $3 \mathrm{~Gy}$ exposure in vivo is estimated to be $10^{-5}-10^{-4}$ based on an extrapolation from high-dose data in lacZ transgenic mice (Nakamura et al, 2000). Although the value seems to be too small to explain the AML incidence, the frequency could be higher if the relevant chromosomal region has a special chromatin structure and is vulnerable to extrinsic insults. Alternatively, it is possible to suppose that the delayed genomic instability is responsible for the

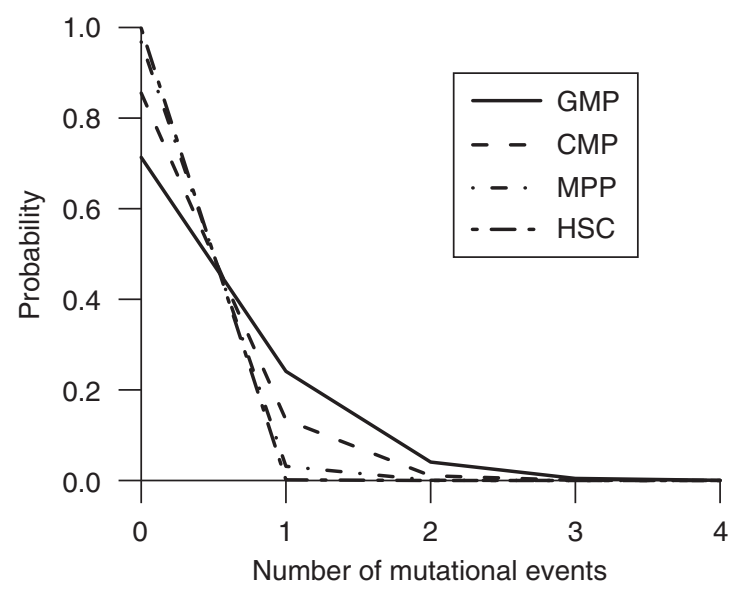

Figure 7 Probability of the AML-specific mutational events in a $3 \mathrm{~Gy}$ exposed mouse during 300 days post irradiation. The probability was calculated from the cumulative number of cell divisions in each cell compartment based on poisson statistics. A constant rate for the AMLspecific Sfpil mutation, I $\times 10^{-9}$ per cell division, was assumed for all cell types.

mutagenesis (Morgan, 2003). In either case, the expected mutation spectrum will be different from that found in AML mice as mentioned earlier, but the discrepancy may be attributable to a clonal selection of the mutants. Even so, however, it is unlikely that very limited clones have a survival advantage because the Sfpil mutations required for the AML development are just an inactivation of the gene. Evidence of a total gene deletion or removal of exon 5 developing into the leukaemia (Silver et al, 1999; Metcalf et al, 2006) implies the particular mutation pattern in the AML mice is not a consequence of clonal selection.

Another possibility is that cells with hemizygous deletion of chromosome 2 acquire a growth advantage and just one or two spontaneous mutagenic events are enough with a large population base of those cells. Haploinsufficiency for Sfpil can bring phenotype alteration enhancing neutrophil progenitor development, but the gene dosage effect is masked in vivo by changes in cytokine expression (Dahl et al, 2003). In fact, clonal analysis of the chromosomal aberrations in irradiated mice indicates no apparent selective or proliferative advantage of hemizygously deleted cells during 12 months after irradiation (Bouffler et al, 1997).

The most plausible explanation will be to allow for the increase in the mutation rate associated with the ageing of stem cells. Our 


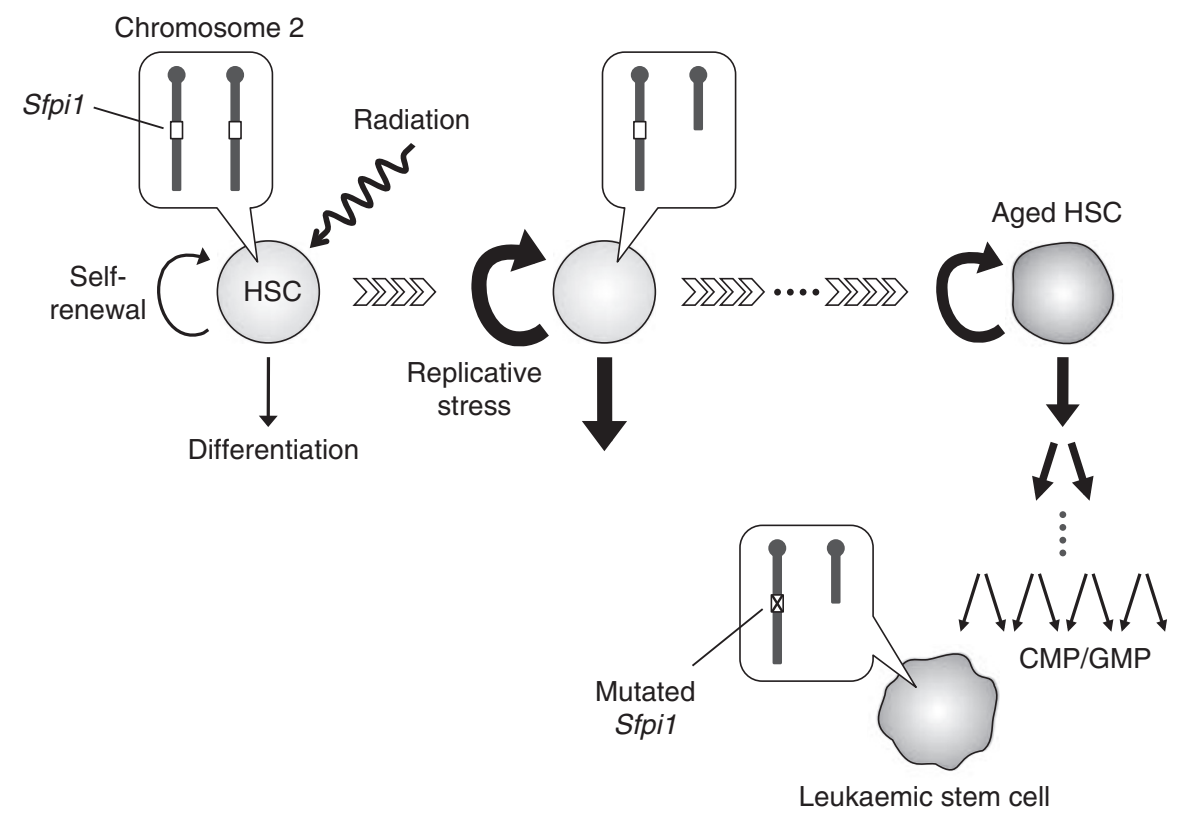

Figure 8 Schematic of proposed model for radiation-induced murine AML. HSCs that escape death by radiation vigourously cycle to reconstitute haematopoiesis. Some of them carry a deletion of chromosome 2, being hemizygous for the Sfpil gene. Enhanced replicative stress promotes ageing of HSCs and the mutation rates gradually increase. On repeated cell divisions with elevated mutation rates, the progeny (CMP or GMP) of an Sfpil -hemizygous HSC spontaneously acquire the AML-specific Sfpil mutation to become a leukaemic stem cell.

simulation predicts that most of the surviving HSCs are recruited into the cell cycle after $3 \mathrm{~Gy}$ exposure, and that the percentage of cycling HSCs remains at $\sim 60 \%$. This contrasts with the cell kinetics of HSCs in the steady state, in which two-thirds of the population are quiescent. Owing to the increased cycling fraction, together with the enhanced mitotic rate, the surviving HSCs in the exposed mouse undergo the extensive rounds of replication. This will make the cells senescent and the mutation accumulation would be accelerated.

There is considerable evidence that continuous replicative stress accelerates the ageing of stem cells, and that aged stem cells are characterised by compromised genome maintenance. Serial transplantation assays in mice have shown that forced stem cell expansion results in deterioration of HSCs (Harrison et al, 1978, 1990; Ross et al, 1982; Spangrude et al, 1995). Functional changes in deteriorated HSCs are comparable to those observed in aged animals - a reduced repopulating ability and preferential differentiation into myeloid lineages (Sudo et al, 2000; Kim et al, 2003). Enhanced proliferation of HSCs caused by gene knockouts also leads to a decline of stem cell functions (Cheng et al, 2000; Hock et al, 2004). Furthermore, a conditional knockout for the Atr gene has showed that even homeostatic proliferation can promote stem-cell dysfunction and ageing (Ruzankina et al, 2007). Therefore, the excessive number of cell divisions in response to haematopoietic demands after irradiation probably promotes the ageing of surviving HSCs. A recent study by Chambers et al has found that the gene expression profile changes as HSCs age, and among the downregulated genes are those involved in the preservation of genomic integrity, such as chromatin remodelling and DNA repair (Chambers et al, 2007). A decline in the expression of those genes will manifest as elevated mutation rates.

We therefore propose a model for murine myeloid leukaemogenesis as shown in Figure 8. Radiation causes cell death of progenitors and stem cells in the haematopoietic system. It also induces chromosomal aberrations and some HSCs survive with a deletion of chromosome 2, being hemizygous for the Sfpil gene. When a substantial fraction of haematopoietic cells are killed by radiation, surviving HSCs vigourously cycle to reconstitute haematopoiesis. Enhanced replicative stress promotes their ageing and mutation rates gradually increase. Random mutations thus accumulate in HSCs during repeated replications unless the mutations bring on a loss of stem cell function. If a leukaemia-specific mutation occurs in an Sfpi1-hemizygous cell in due course, the cell becomes a leukaemic stem cell. As the leukaemic stem cells can arise not only from HSCs, but also from CMPs and GMPs (Passegué and Weisman, 2005), those outnumbering cells are more likely to be the origin of AMLs if the elevated mutation rates of HSCs are inherited by the progeny. Although the model does not exclude the possibility that the deletion of chromosome 2 arises from delayed instability, it is more reasonable to presume an early formation of the aberration unless the spontaneous mutation rates increase enormously.

According to this model, the induction pattern of AML could be modified by changing the cell kinetics of haematopoietic cells. For example, the latency of AML development will be longer and the lifetime incidence will decrease if cycling rates of HSCs are slowed down after irradiation. This has actually been showed by dietary restriction in mice. Under caloric restriction, the cycling fraction of haematopoietic stem/progenitor cells is low (Yoshida et al, 2006) and senescence of HSCs is postponed (Chen et al, 2003). When exposed to radiation, those mice show a delayed onset and lower incidence of AML compared with mice without caloric restriction (Yoshida et al, 1997). Moreover, onset delay and significant decrease in incidence are not observed in mice with pre-irradiation restriction, but only with post-irradiation restriction (Yoshida et al, 2006). All these findings are consistent with the proposed model.

Finally, we should note the limitations of our mathematical analysis. We consulted the literature for realistic parameter values, but available data were limited and arbitrary values had to be assigned to some parameters. In addition, there are factors not taken into account in the analysis; that is spontaneous cell death/ inactivation, cell kinetics change because of natural ageing, strain difference in cell kinetics, and radiation effects on stromal cells. 
The accumulation of empirical data will enable a more realistic simulation integrating those factors. However, despite these limitations, it is certain that surviving HSCs have to cycle at enhanced rates to recover and maintain haematopoiesis after irradiation. We therefore conclude that the acceleration of HSC ageing because of continuous replicative stress is a major effect of irradiation in murine leukaemogenesis.

\section{ACKNOWLEDGEMENTS}

The authors thank Naomi Adachi for her help with the experimental work.

Supplementary Information accompanies the paper on British Journal of Cancer website (http://www.nature.com/bjc)

\section{REFERENCES}

Ban N, Kai M, Kusama T (1997) Chromosome aberrations in bone marrow cells of $\mathrm{C} 3 \mathrm{H} / \mathrm{He}$ mice at an early stage after whole-body irradiation. J Radiat Res (Tokyo) 38: 219-231

Bouffler SD, Haines JW, Edwards AA, Harrison JD, Cox R (2001) Lack of detectable transmissible chromosomal instability after in vivo or in vitro exposure of mouse bone marrow cells to ${ }^{224} \mathrm{Ra}$ alpha particles. Radiat Res 155: $345-352$

Bouffler SD, Meijne EI, Morris DJ, Papworth D (1997) Chromosome 2 hypersensitivity and clonal development in murine radiation acute myeloid leukaemia. Int J Radiat Biol 72: 181 - 189

Boulton E, Cleary H, Papworth D, Plumb M (2001) Susceptibility to radiation-induced leukaemia/lymphoma is genetically separable from sensitivity to radiation-induced genomic instability. Int J Radiat Biol 77: $21-29$

Bowie MB, McKnight KD, Kent DG, McCaffrey L, Hoodless PA, Eaves CJ (2006) Hematopoietic stem cells proliferate until after birth and show a reversible phase-specific engraftment defect. J Clin Invest 116: $2808-2816$

Bradford GB, Williams B, Rossi R, Bertoncello I (1997) Quiescence, cycling, and turnover in the primitive hematopoietic stem cell compartment. Exp Hematol 25: $445-453$

Breems DA, Blokland EA, Neben S, Ploemacher RE (1994) Frequency analysis of human primitive haematopoietic stem cell subsets using a cobblestone area forming cell assay. Leukemia 8: 1095-1104

Busuttil RA, Rubio M, Dollé MET, Campisi J, Vijg J (2003) Oxygen accelerates the accumulation of mutations during the senescence and immortalization of murine cells in culture. Aging Cell 2: 287-294

Chambers SM, Shaw CA, Gatza C, Fisk CJ, Donehower LA, Goodell MA (2007) Aging hematopoietic stem cells decline in function and exhibit epigenetic dysregulation. PLoS Biol 5: e201

Chen J, Astle CM, Harrison DE (2003) Hematopoietic senescence is postponed and hematopoietic stem cell function is enhanced by dietary restriction. Exp Hematol 31: $1097-1103$

Cheng T, Rodrigues N, Shen H, Yang Y, Dombkowski D, Sykes M, Scadden DT (2000) Hematopoietic stem cell quiescence maintained by p21cip1/ waf1. Science 287: $1804-1808$

Clark DJ, Meijne EI, Bouffler SD, Huiskamp R, Skidmore CJ, Cox R, Silver AR (1996) Microsatellite analysis of recurrent chromosome 2 deletions in acute myeloid leukaemia induced by radiation in F1 hybrid mice. Genes Chromosomes Cancer 16: 238-246

Cook WD, McCaw BJ, Herring C, John DL, Foote SJ, Nutt SL, Adams JM (2004) PU.1 is a suppressor of myeloid leukemia, inactivated in mice by gene deletion and mutation of its DNA binding domain. Blood 104: $3437-3444$

Dahl R, Walsh JC, Lancki D, Laslo P, Iyer SR, Singh H, Simon MC (2003) Regulation of macrophage and neutrophil cell fates by the PU.1:C/ EBPalpha ratio and granulocyte colony-stimulating factor. Nat Immunol 4: $1029-1036$

de Haan G, Nijhof W, Van Zant G (1997) Mouse strain-dependent changes in frequency and proliferation of hematopoietic stem cells during aging correlation between lifespan and cycling activity. Blood 89: $1543-1550$

Douglas GR, Gingerich JD, Gossen JA, Bartlett SA (1994) Sequence spectra of spontaneous lacZ gene mutations in transgenic mouse somatic and germline tissues. Mutagenesis 9: 451-458

Eaves C, Miller C, Cashman J, Conneally E, Petzer A, Zandstra P, Eaves A (1997) Hematopoietic stem cells: inferences from in vivo assays. Stem Cells 15(Suppl 1): $1-5$

Habibian HK, Peters SO, Hsieh CC, Wuu J, Vergilis K, Grimaldi CI, Reilly J, Carlson JE, Frimberger AE, Stewart FM, Quesenberry PJ (1998) The fluctuating phenotype of the lymphohematopoietic stem cell with cell cycle transit. J Exp Med 188: $393-398$
Harrison DE, Astle CM, Delaittre JA (1978) Loss of proliferative capacity in immunohemopoietic stem cells caused by serial transplantation rather than aging. $J$ Exp Med 147: 1526-1531

Harrison DE, Stone M, Astle CM (1990) Effects of transplantation on the primitive immunohematopoietic stem cell. J Exp Med 172: $431-437$

Hayata I (1985) Leukemogenesis and chromosomal abnormalities: experimental animals. Nippon Ketsueki Gakkai Zasshi 48: 1857-1863

Hayata I, Seki M, Yoshida K, Hirashima K, Sado T, Yamagiwa J, Ishihara T (1983) Chromosomal aberrations observed in 52 mouse myeloid leukemias. Cancer Res 43: $367-373$

Hirouchi T, Takabatake T, Yoshida K, Nitta Y, Nakamura M, Tanaka S, Ichinohe K, Oghiso Y, Tanaka K (2008) Upregulation of c-myc gene accompanied by PU.1 deficiency in radiation-induced acute myeloid leukemia in mice. Exp Hematol 36: 871 - 885

Hock H, Hamblen MJ, Rooke HM, Schindler JW, Saleque S, Fujiwara Y, Orkin SH (2004) Gfi-1 restricts proliferation and preserves functional integrity of haematopoietic stem cells. Nature 431: $1002-1007$

Kamminga LM, de Haan G (2006) Cellular memory and hematopoietic stem cell aging. Stem Cells 24: $1143-1149$

Kim M, Moon H, Spangrude GJ (2003) Major age-related changes of mouse hematopoietic stem/progenitor cells. Ann N Y Acad Sci 996: 195-208

Kunkel TA, Bebenek K (2000) DNA replication fidelity. Annu Rev Biochem 69: $497-529$

Little JB (2000) Radiation carcinogenesis. Carcinogenesis 21: $397-404$

Lorimore SA, Wright EG (1990) Late effects of X-irradiation on haemopoietic stem cells in CBA/H mice. Int J Radiat Biol 57: $385-393$

Major IR (1979) Induction of myeloid leukaemia by whole-body single exposure of CBA male mice to X-rays. Br J Cancer 40: 903-913

Meijne EI, van der Winden-van Groenewegen RJ, Ploemacher RE, Vos O, David JA, Huiskamp R (1991) The effects of x-irradiation on hematopoietic stem cell compartments in the mouse. Exp Hematol 19: $617-623$

Metcalf D, Dakic A, Mifsud S, Di Rago L, Wu L, Nutt S (2006) Inactivation of PU.1 in adult mice leads to the development of myeloid leukemia. Proc Natl Acad Sci USA 103: 1486-1491

Mole RH, Papworth DG, Corp MJ (1983) The dose-response for x-ray induction of myeloid leukaemia in male CBA/H mice. Br J Cancer 47: 285-291

Morgan WF (2003) Non-targeted and delayed effects of exposure to ionizing radiation: II. Radiation-induced genomic instability and bystander effects in vivo, clastogenic factors and transgenerational effects. Radiat Res 159: 581-596

Mrózek K, Heerema NA, Bloomfield CD (2004) Cytogenetics in acute leukemia. Blood Rev 18: $115-136$

Nakamura N (2005) A hypothesis: radiation-related leukemia is mainly attributable to the small number of people who carry pre-existing clonally expanded preleukemic cells. Radiat Res 163: 258-265

Nakamura S, Ikehata H, Komura J, Hosoi Y, Inoue H, Gondo Y, Yamamoto K, Ichimasa Y, Ono T (2000) Radiation-induced mutations in the spleen and brain of lacZ transgenic mice. Int J Radiat Biol 76: 431 - 440

Olesen G, Tønder H, Palshof T, Hokland P (2002) Peripheral blood accessory cells modulate committed colony-forming units but not 5-week cobblestone-area-forming cell outgrowth from CD34+ cells. Eur J Haematol 68: 65-72

Parmar K, Burdick D, Ethier M, Clyne J, Mauch P (2005) Murine side population cells contain cobblestone area-forming cell activity in mobilized blood. Stem Cells Dev 14: $452-461$

Passegué E, Wagers AJ, Giuriato S, Anderson WC, Weissman IL (2005) Global analysis of proliferation and cell cycle gene expression in the regulation of hematopoietic stem and progenitor cell fates. $J$ Exp Med 202: $1599-1611$ 
Passegué E, Weisman IL (2005) Leukemic stem cells: where do they come from? Stem Cell Rev 1: $181-188$

Peng Y, Brown N, Finnon R, Warner CL, Liu X, Genik PC, Callan MA, Ray FA, Borak TB, Badie C, Bouffler SD, Ullrich RL, Bedford JS, Weil MM (2009) Radiation leukemogenesis in mice: loss of PU.1 on chromosome 2 in CBA and C57BL/6 mice after irradiation with $1 \mathrm{GeV} /$ nucleon $56 \mathrm{Fe}$ ions, $\mathrm{X}$ rays or gamma rays. Part I. Experimental observations. Radiat Res 171: $474-483$

Ploemacher RE, van der Sluijs JP, Voerman JS, Brons NH (1989) An in vitro limiting-dilution assay of long-term repopulating hematopoietic stem cells in the mouse. Blood 74: 2755-2763

Ploemacher RE, van der Sluijs JP, van Beurden CA, Baert MR, Chan PL (1991) Use of limiting-dilution type long-term marrow cultures in frequency analysis of marrow-repopulating and spleen colony-forming hematopoietic stem cells in the mouse. Blood 78: 2527-2533

Plumb M, Cleary H, Wright E (1998) Genetic instability in radiationinduced leukaemias: mouse models. Int J Radiat Biol 74: 711-720

Preston DL, Kusumi S, Tomonaga M, Izumi S, Ron E, Kuramoto A, Kamada N, Dohy H, Matsuo T, Matsui T, [corrected to Matsuo T] (1994) Cancer incidence in atomic bomb survivors. Part III. Leukemia, lymphoma and multiple myeloma, 1950-1987. Radiat Res 137: S68-S97

Resnitzky P, Estrov Z, Haran-Ghera N (1985) High incidence of acute myeloid leukemia in SJL/J mice after X-irradiation and corticosteroids. Leuk Res 9: $1519-1528$

Rithidech KN, Bond VP, Cronkite EP, Thompson MH (1993) A specific chromosomal deletion in murine leukemic cells induced by radiation with different qualities. Exp Hematol 21: 427-431

Rosenbauer F, Wagner K, Kutok JL, Iwasaki H, Le Beau MM, Okuno Y, Akashi K, Fiering S, Tenen DG (2004) Acute myeloid leukemia induced by graded reduction of a lineage-specific transcription factor, PU.1. Nat Genet 36: 624-630

Ross EA, Anderson N, Micklem HS (1982) Serial depletion and regeneration of the murine hematopoietic system. Implications for hematopoietic organization and the study of cellular aging. J Exp Med 155: $432-444$

Rossi DJ, Bryder D, Seita J, Nussenzweig A, Hoeijmakers J, Weissman IL (2007) Deficiencies in DNA damage repair limit the function of haematopoietic stem cells with age. Nature 447: 725-729

Ruzankina Y, Pinzon-Guzman C, Asare A, Ong T, Pontano L, Cotsarelis G, Zediak VP, Velez M, Bhandoola A, Brown EJ (2007) Deletion of the developmentally essential gene ATR in adult mice leads to age-related phenotypes and stem cell loss. Cell Stem Cell 1: 113-126

Sankaranarayanan K (1991) Ionizing radiation and genetic risks. III. Nature of spontaneous and radiation-induced mutations in mammalian in vitro systems and mechanisms of induction of mutations by radiation. Mutat Res 258: 75 - 97

Schoch C, Haferlach T (2002) Cytogenetics in acute myeloid leukemia. Curr Oncol Rep 4: 390-397

Seki M, Yoshida K, Nishimura M, Nemoto K (1991) Radiation-induced myeloid leukemia in $\mathrm{C} 3 \mathrm{H} / \mathrm{He}$ mice and the effect of prednisolone acetate on leukemogenesis. Radiat Res 127: 146-149

Sharpless NE, DePinho RA (2007) How stem cells age and why this makes us grow old. Nat Rev Mol Cell Biol 8: 703-713
Silver A, Moody J, Dunford R, Clark D, Ganz S, Bulman R, Bouffler S, Finnon P, Meijne E, Huiskamp R, Cox R (1999) Molecular mapping of chromosome 2 deletions in murine radiation-induced AML localizes a putative tumor suppressor gene to a $1.0 \mathrm{cM}$ region homologous to human chromosome segment 11p11-12. Genes Chromosomes Cancer 24: $95-104$

Spangrude GJ, Brooks DM, Tumas DB (1995) Long-term repopulation of irradiated mice with limiting numbers of purified hematopoietic stem cells: in vivo expansion of stem cell phenotype but not function. Blood 85: $1006-1016$

Spangrude GJ, Johnson GR (1990) Resting and activated subsets of mouse multipotent hematopoietic stem cells. Proc Natl Acad Sci USA 87: $7433-7437$

Sudo K, Ema H, Morita Y, Nakauchi H (2000) Age-associated characteristics of murine hematopoietic stem cells. J Exp Med 192: $1273-1280$

Suraweera N, Meijne E, Moody J, Carvajal-Carmona LG, Yoshida K, Pollard P, Fitzgibbon J, Riches A, van Laar T, Huiskamp R, Rowan A, Tomlinson IP, Silver A (2005) Mutations of the PU.1 Ets domain are specifically associated with murine radiation-induced, but not human therapyrelated, acute myeloid leukaemia. Oncogene 24: 3678-3683

Tejero C, Hendry JH, Testa NG (1988) Persistent dose-dependent increases in cycling of haemopoietic precursor cells after irradiation. Cell Tissue Kinet 21: $201-204$

Thacker J (1986) The nature of mutants induced by ionising radiation in cultured hamster cells. III. Molecular characterization of HPRT-deficient mutants induced by gamma-rays or alpha-particles showing that the majority have deletions of all or part of the hprt gene. Mutat Res 160: $267-275$

Trakhtenbrot L, Krauthgamer R, Resnitzky P, Haran-Ghera N (1988) Deletion of chromosome 2 is an early event in the development of radiation-induced myeloid leukemia in SJL/J mice. Leukemia 2: $545-550$

Upton AC, Wolff FF, Furth J, Kimball AW (1958) A comparison of the induction of myeloid and lymphoid leukemias in $\mathrm{x}$-radiated RF mice. Cancer Res 18: $842-848$

Ushijima T, Hosoya Y, Ochiai M, Kushida H, Wakabayashi K, Suzuki T, Hayashi M, Sofuni T, Sugimura T, Nagao M (1994) Tissue-specific mutational spectra of 2-amino-3,4-dimethylimidazo[4,5-f]quinoline in the liver and bone marrow of lacI transgenic mice. Carcinogenesis 15: $2805-2809$

Wright EG (1998) Radiation-induced genomic instability in haemopoietic cells. Int J Radiat Biol 74: $681-687$

Yoshida K, Inoue T, Nojima K, Hirabayashi Y, Sado T (1997) Calorie restriction reduces the incidence of myeloid leukemia induced by a single whole-body radiation in $\mathrm{C} 3 \mathrm{H} / \mathrm{He}$ mice. Proc Natl Acad Sci USA 94: $2615-2619$

Yoshida K, Hirabayashi Y, Watanabe F, Sado T, Inoue T (2006) Caloric restriction prevents radiation-induced myeloid leukemia in $\mathrm{C} 3 \mathrm{H} / \mathrm{HeMs}$ mice and inversely increases incidence of tumor-free death: implications in changes in number of hemopoietic progenitor cells. Exp Hematol 34: $274-283$ 